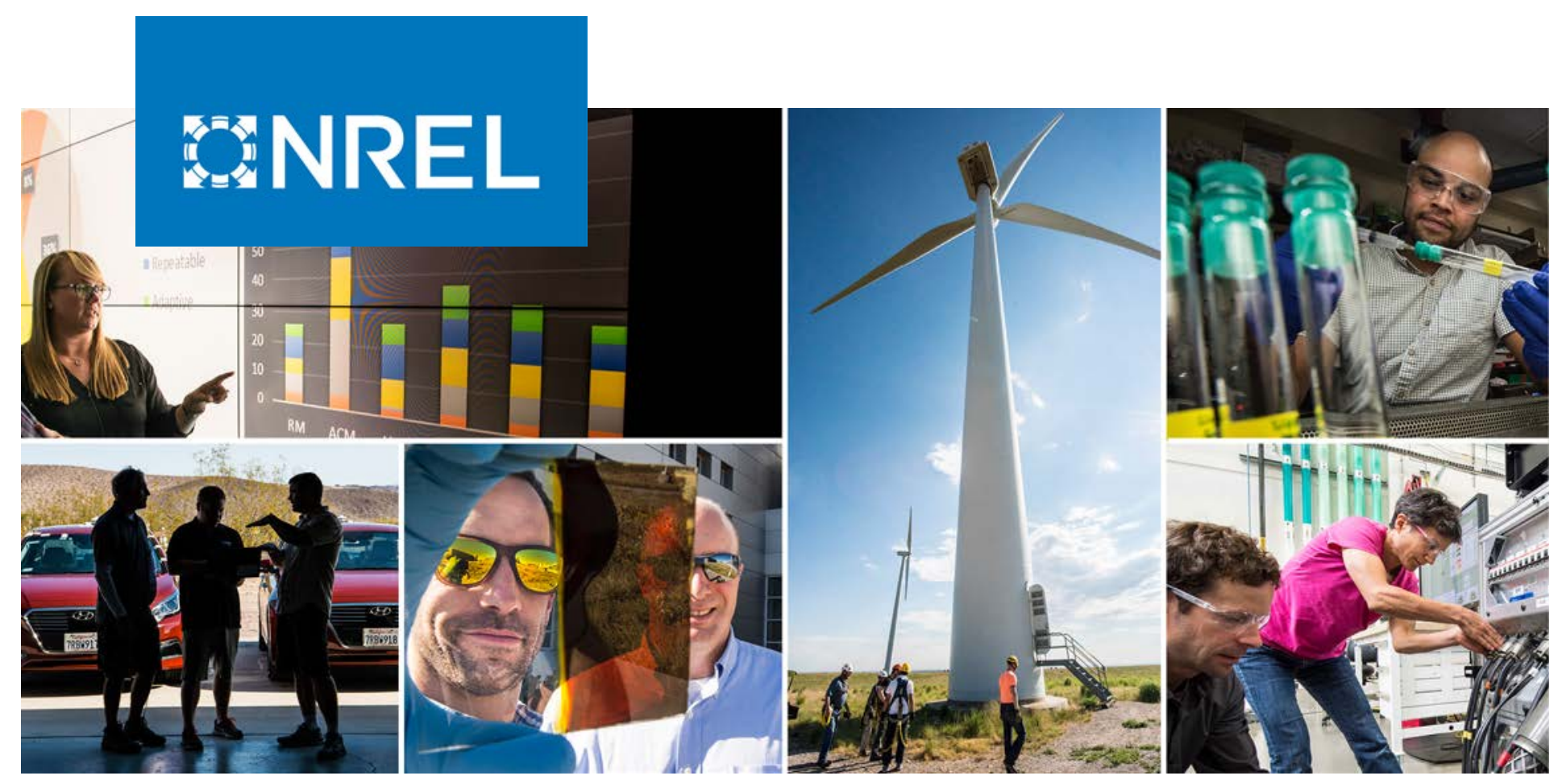

\title{
Techno-Economic Assessment for Opportunities to Integrate Algae Farming with Wastewater Treatment
}

Jennifer Clippinger and Ryan Davis

National Renewable Energy Laboratory

NREL is a national laboratory of the U.S. Department of Energy Office of Energy Efficiency \& Renewable Energy

Operated by the Alliance for Sustainable Energy, LLC

This report is available at no cost from the National Renewable Energy Laboratory (NREL) at www.nrel.gov/publications.
Technical Report

NREL/TP-5100-75237

September 2021 


\section{GNREL}

Techno-Economic Assessment for Opportunities to Integrate Algae Farming with Wastewater Treatment

Jennifer Clippinger and Ryan Davis

National Renewable Energy Laboratory

\section{Suggested Citation}

Clippinger, Jennifer, and Ryan Davis. 2021. Techno-Economic Assessment for Opportunities to Integrate Algae Farming with Wastewater Treatment. Golden, CO: National Renewable Energy Laboratory. NREL/TP-5100-75237.

https://www.nrel.gov/docs/fy210sti/75237.pdf.

NREL is a national laboratory of the U.S. Department of Energy Office of Energy Efficiency \& Renewable Energy Operated by the Alliance for Sustainable Energy, LLC

This report is available at no cost from the National Renewable Energy Laboratory (NREL) at www.nrel.gov/publications.

Contract No. DE-AC36-08GO28308
Technical Report

NREL/TP-5100-75237

September 2021

National Renewable Energy Laboratory 15013 Denver West Parkway Golden, CO 80401

303-275-3000 • www.nrel.gov 


\section{NOTICE}

This work was authored in part by the National Renewable Energy Laboratory, operated by Alliance for Sustainable Energy, LLC, for the U.S. Department of Energy (DOE) under Contract No. DE-AC36-08GO28308. Funding provided by U.S. Department of Energy Office of Energy Efficiency and Renewable Energy Bioenergy Technologies Office. The views expressed herein do not necessarily represent the views of the DOE or the U.S. Government.

This report is available at no cost from the National Renewable Energy Laboratory (NREL) at www.nrel.gov/publications.

U.S. Department of Energy (DOE) reports produced after 1991 and a growing number of pre-1991 documents are available free via www.OSTI.gov.

Cover Photos by Dennis Schroeder: (clockwise, left to right) NREL 51934, NREL 45897, NREL 42160, NREL 45891, NREL 48097, NREL 46526.

NREL prints on paper that contains recycled content. 


\section{Acknowledgments}

We gratefully acknowledge guidance and inputs furnished through discussions with MicroBio Engineering (Kyle Poole, Ian Woertz, Tryg Lundquist, and John Benemann) and

NeoChloris/University of Illinois at Urbana-Champaign (Charles Stack, Prasad Kodukula, and Lance Schideman) for helpful information utilized in conducting this analysis. We also thank collaborators from Gross-Wen Technologies (Jens Dancer and Martin Gross) for providing additional feedback during final review of this report. 


\section{List of Acronyms}

$\$ / \mathrm{lb}$

AD

AFDW

BGD

BGGE/yr

BOD

CAP

CHNOSP

$\mathrm{CO}_{2}$

COD

EPA

g/day

$\mathrm{g} / \mathrm{L}$

$\mathrm{g} / \mathrm{m}^{2} /$ day

GGE

HCSD

HPSD

MBSP

$\mathrm{mg} / \mathrm{L}$

MG

MGD

MM

$\mathrm{N} / \mathrm{P}$

NREL

O\&M

PBR

TEA

tons/yr

WWT

WWTP dollars per pound

anaerobic digestion

ash-free dry weight

billion gallons per day

billion gallons gasoline equivalent per year

biochemical oxygen demand

combined algal processing

carbon, hydrogen, nitrogen, oxygen, sulfur, phosphorus

carbon dioxide

chemical oxygen demand

U.S. Environmental Protection Agency

grams per day

grams per liter

grams per square meter per day

gallon gasoline equivalent

high-carbohydrate Scenedesmus

high-protein Scenedesmus

minimum biomass selling price

milligrams per liter

million gallons

million gallons per day

million

nitrogen and phosphorus

National Renewable Energy Laboratory

operations and maintenance

photobioreactor

techno-economic analysis

tons per year

wastewater treatment

wastewater treatment plant 


\section{Executive Summary}

This report describes the investigation of the economic and scalability potential for algal biomass production based on opportunities to couple algae farming with wastewater treatment (WWT). This activity was motivated in part by recent increased attention in both the research communities and industry for utilizing algae to treat municipal wastewater, in many cases projecting substantial economic potential for algal WWT relative to other more traditional WWT methods. While typically those perspectives appropriately view treated wastewater as the primary product output and algal biomass as a secondary coproduct, to enable a consistent comparison against NREL's standard algae farm models (i.e. solving for minimum biomass selling price (MBSP) for a farm configured to maximize biomass production while minimizing water footprint sourced from a local groundwater resource), the algal WWT cases evaluated in this study also solved for MBSP while assigning a treatment coproduct credit as a means to valorize the treated water. From a techno-economic analysis perspective taking the viewpoint of the algae farm, algal WWT offers two primary advantages over traditional algal biomass cultivation:

1. A large fraction of nutrients, as well as a portion of carbon, required for meeting algal biomass compositional demands are met "for free" based on nutrients and organic carbon in the incoming wastewater. These are otherwise required to be purchased as fertilizers and carbon dioxide $\left(\mathrm{CO}_{2}\right)$, which typically constitute roughly $\$ 100 /$ ton or more of biomass production costs.

2. Significant revenue can be generated as wastewater treatment "coproduct credits" in the form of avoided expenses, which would otherwise be incurred to construct new or more elaborate WWT facilities using traditional technologies.

However, being constrained to a finite wastewater capacity, this analysis also considers implications for national scalability for this concept with respect to total biomass or biofuel production potential.

Two scenarios were considered for potential integration points into a typical wastewater treatment facility configuration: one based on replacing the majority of standard WWT operations to perform complete "bulk" wastewater treatment, and a second based on adding new/additional tertiary treatment capabilities to target more comprehensive removal specifically of nitrogen and phosphorus (N/P), including to more stringent levels attributed to recent regulatory requirements. The majority of cases evaluated under both scenarios found highly favorable economics with MBSPs generally under \$100/ton and many even calculated as negative MBSPs, i.e., the revenues generated for treating wastewater (calculated in this study as a coproduct credit) outweigh all biomass production costs such that the facility is still profitable without any revenue required from selling the biomass. The tertiary treatment approach was seen to generate more significant revenues and lower potential MBSPs than complete WWT. In contrast, this may be compared to traditional algae farm model targets at $\$ 488 /$ ton, reflecting open pond algae farms dedicated to biomass production with external purchase of nutrients, $\mathrm{CO}_{2}$, and water sourcing.

However, particularly when focused on higher protein (higher N/P) compositions, which are likely more realistic for this particular context focused on continuous treatment of wastewater nutrients, the lower amount of biomass produced per ton of N/P available after considering national wastewater production volumes translates to an upper limit on national scalability 
potential. Based on existing and projected future wastewater capacity flows, base case estimates indicate roughly 4-6 million (MM) tons/yr of algal biomass production potential for the "complete" WWT case reducing to roughly $2 \mathrm{MM}$ tons/yr for the tertiary treatment case. This would translate to roughly 300-500 MM gallon gasoline equivalent (GGE)/yr or 100-200 MM GGE/yr total biofuel capacity for the two respective scenarios. Accordingly, this preliminary assessment finds agreement with other claims around the economic incentives for algal WWT as a sensible approach to take in the near-term at smaller scales, thus providing in-roads to begin developing algae industry capacity and experience; but may not necessarily achieve by itself a broader capacity for algae to provide more substantial contributions to national biomass/biofuel volumes on the order of 5 billion GGE/yr as may be achievable when removing wastewater availability constraints, relative to total U.S. transportation fuel consumption around 230 billion GGE/yr. However, additional waste resources with comparable or larger volumes, such as livestock waste, may offer additional opportunities for similar algal remediation approaches with further environmental benefits. 


\section{Contents}

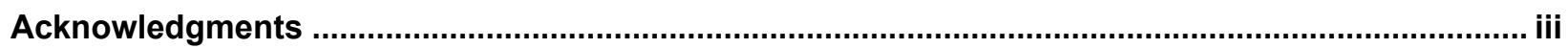

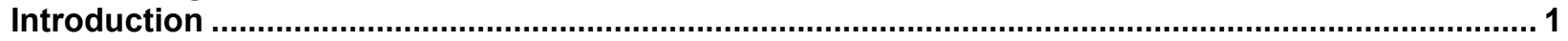

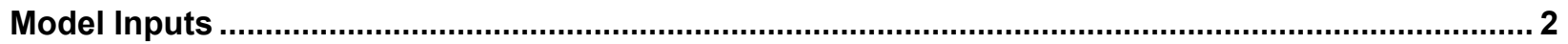

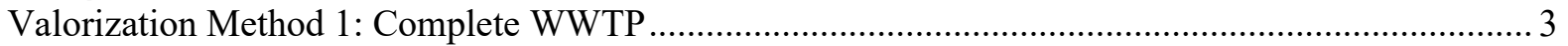

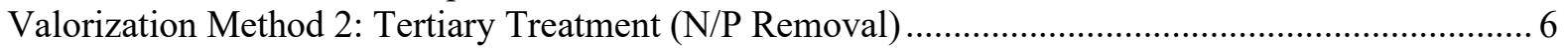

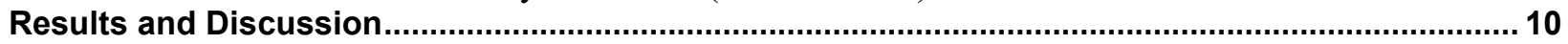

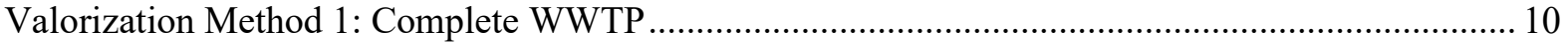

Valorization Method 2: Tertiary Treatment (N/P Removal) ........................................................... 12

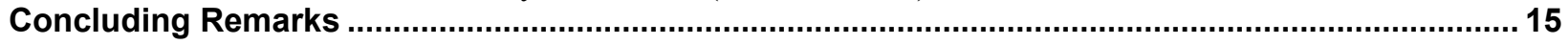

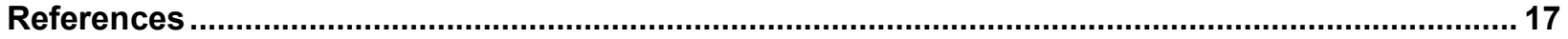




\section{Introduction}

The National Renewable Energy Laboratory (NREL) has spent the last several years evaluating algae production and conversion technologies to support research targets for economical algal fuel production. These techno-economic analyses (TEAs) consider both algae cultivation and dewatering (known as the algae "farm" design) and conversion through combined algal processing (CAP) with off-shoots and sensitivities of these analyses considering new concepts or alternative processing approaches [1-3]. In 2016, NREL published a design report on algae biomass cultivation in open ponds and downstream dewatering [2]. The design stipulated a single algae strain cultivated year-round autotrophically. Following this effort, NREL worked congruently with Argonne National Laboratory and Pacific Northwest National Laboratory on harmonizing updated process model assumptions [3]. Specifically, resource analysis and strain rotation with algae that can grow in fresh or saline/brackish water were modeled, while maintaining standard cultivation assumptions around sourcing nutrient inputs from external fertilizers at added cost. As an alternative to traditional algal cultivation on fresh or saline water with supplemental carbon dioxide $\left(\mathrm{CO}_{2}\right)$ and nutrient supply, cultivation using wastewater is another possibility but was not included in the prior harmonization work scope.

Within the United States, there are over 15,000 publicly owned wastewater treatment (WWT) facilities that collectively treat over 34.5 billion gallons of water per day [4]. Wastewater contains nutrients such as carbon, nitrogen $(\mathrm{N})$, and phosphorus $(\mathrm{P})$ that can be utilized for algae production to reduce external purchase costs for those components, while providing a service to remove those contaminants from the wastewater, which must otherwise be treated through alternative methods (in some cases at significant expense, depending on the regulation for treated water discharge limits) [5,6]. In microalgae-based wastewater treatment, the algae produce dissolved oxygen, which aids in the oxidation of waste organic matter, while assimilating $\mathrm{N}$ and $P$. Thus, by growing algae in wastewater, treatment can be accomplished concurrently with biomass production. Algae wastewater treatment plants using deep ponds are common (of the above-cited 15,000 WWT facilities, approximately half include ponds supporting microalgae), but they generally are not designed to produce a harvestable algae biomass. In light of these considerations, a growing number of industry entities have begun to develop systems for intensive algal wastewater remediation, claiming significant economic incentives for enabling cost-competitive processes [5,6]. Given such recent industry expansion into this area, we desired to better understand the quantitative drivers and differences from a TEA standpoint around algal wastewater cultivation relative to traditional TEA farm models. The present analysis provides a preliminary TEA assessment, as well as resource potential extrapolations, for algae cultivation to treat wastewater across two separate integration points tying into typical wastewater treatment operations. The TEA is limited here to open pond systems for algal cultivation to provide preliminary proof-of-concept, but closed photobioreactor (PBR) systems are also applicable and are being developed commercially for this application, as they also may enable unlocking opportunities for algal cultivation in more northern climates where cold temperatures and low wintertime solar irradiance would limit deployment of open pond systems. 


\section{Model Inputs}

The following discussion summarizes a general overview of a wastewater treatment plant (WWTP) with considerations of streams within the process where algae production could be integrated, as evaluated across two methods for valorizing wastewater remediation. With over 15,000 WWTPs in the United States, facility designs can be highly individualized and unique depending on several factors such as location, feed streams, and final water quality regulations [4]. In general, Figure 1 shows a block-flow diagram for the most commonly encountered process steps within an activated sludge WWTP. Raw municipal wastewater from multiple point sources combine and enter the facility where a series of screens, grit chambers, and finally grinders produce an untreated wastewater with a high percentage of suspended solids. This material enters a primary clarifier. Settled solids from primary clarification then flow to a thickening unit to increase the solids concentration as a sludge stream. The supernatant from the thickener returns to the primary clarification unit while the sludge flows to an anaerobic digestion (AD) unit to reduce the biochemical oxygen demand (BOD); the AD step is outside the analysis boundaries of this effort, focused on options to handle clarified effluent water either following primary or secondary clarification. Final AD sludge is trucked off-site for disposal while the $\mathrm{AD}$ centrate returns to the primary clarification unit. The liquid stream from the primary clarification (stream 6 in Figure 1) contains additional carbon and nutrients, which are absorbed and oxidized by activated sludge in an aerobic basin. The product from the aerobic bioreactor, activated sludge, is made up of microbial biomass. The produced solids from the activated sludge step settle in a secondary clarification unit and a fraction of the activated sludge returns to the aerobic basin while the remainder flows to the sludge thickening unit. The liquid effluent from the secondary clarification unit may meet water quality regulations, but if not, a series of tertiary treatment steps may be implemented to further treat the water to limits set by local governing regulations.

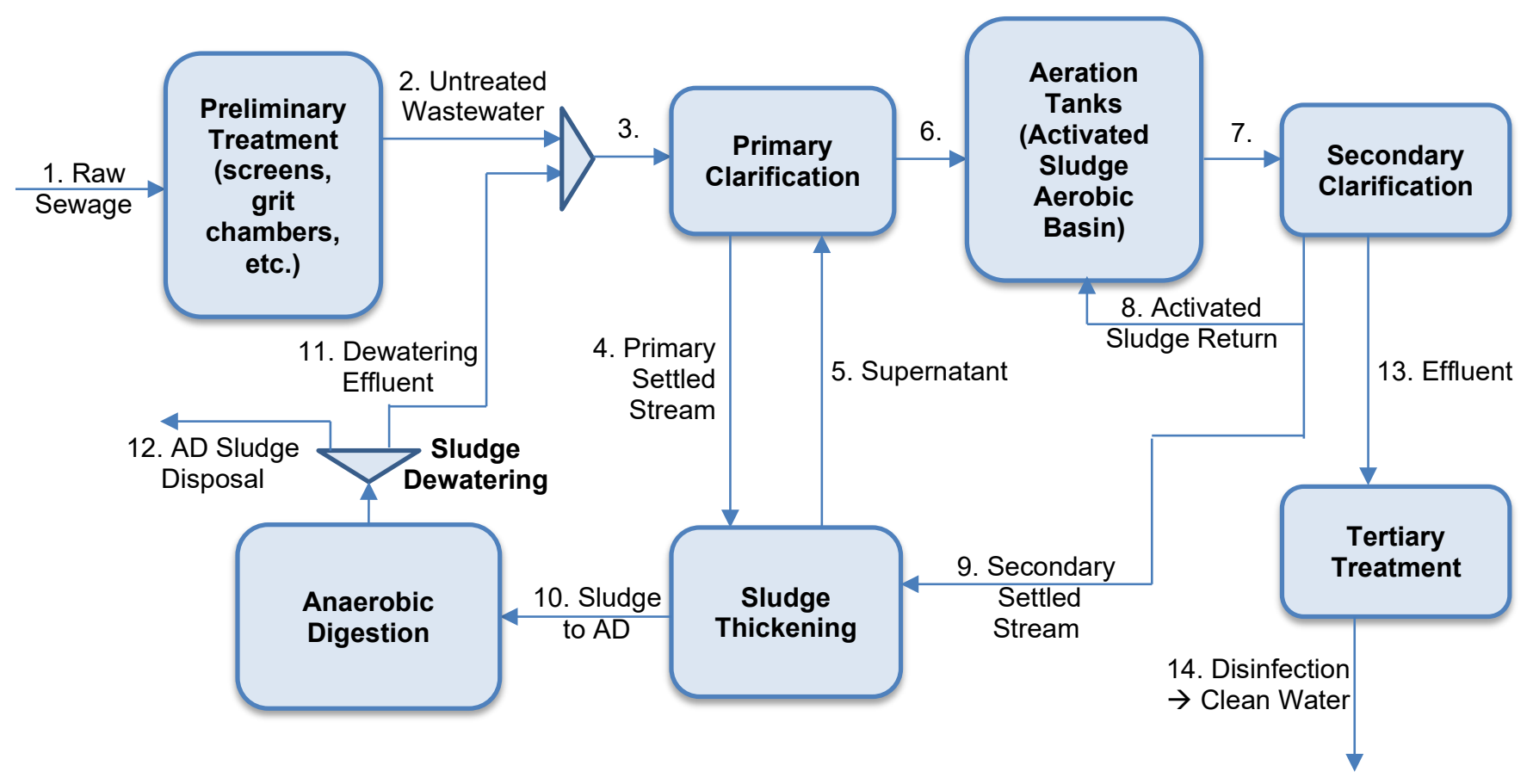

Figure 1. Typical block-flow diagram of an activated sludge wastewater treatment facility 
Algae cultivation for WWT holds the potential to both treat water as well as produce algal biomass, which may be viewed as a value-added coproduct from the perspective of the WWT facility. (However, given the presence of numerous possible wastewater contaminants likely to be present along with the harvested algae, downstream utilization options for the biomass would likely be limited to fuel/energy combustion, $\mathrm{AD}$, or other routes through biomass destruction). There are several possible integration points within the WWTP where streams can be diverted to a co-located algae cultivation facility. For one, instead of recycling the high-nutrient AD centrate, it could instead serve as the main feed stream to the algae facility. AD centrate is often roughly $1 \%$ of the incoming untreated wastewater flow rate [7]. In this approach, the algae facility does not replace any WWT process steps, but reduces the overall nutrient removal load on the WWTP. Although this could be an option for consideration, the cost benefits for a WWTP are not directly intuitive for this approach. A WWTP would need to be consulted to inform the design and how the operating expenditures and circulated nutrient loadings would change due to the AD centrate stream diversion. Due to its small flow rate of the total WWTP and difficulty in establishing a direct cost benefit, we did not consider AD centrate as a main scenario feeding into the algae cultivation system. A second option is to replace the majority of the WWTP configuration with an algae cultivation process that can grow mixotrophically (on both organic carbon in the wastewater and supplemental inorganic $\mathrm{CO}_{2}$ ). After preliminary treatment and primary clarification in Figure 1, the algae farm could directly utilize the clarified effluent. This would replace the need for the aeration tanks, secondary clarification, AD, and tertiary treatment. In this method (termed here as "complete WWTP replacement" and described in greater detail below), the treated water produced from the algae facility would be sold as a coproduct to customers. Under this scenario, a polyculture would be cultivated consisting of both algae and other heterotrophic biomass, with the focus of discussion here-regarding "biomass" productivity, national "biomass" resource potential, etc. - intended to focus on the algae portion of the cultivated biomass. Finally, the algae facility could also use the effluent from secondary clarification and replace the need for other expensive nutrient removal units in situations where further wastewater remediation is required (for example, in meeting removal of $\mathrm{N}$ and $\mathrm{P}$ under more stringent discharge limits being implemented currently) [5]. This second valorization option, tertiary treatment, is also considered and described in more detail below.

\section{Valorization Method 1: Complete WWTP}

Figure 2 depicts the proposed changes to a WWTP for on-site algae cultivation that utilizes the primary effluent stream. The algae cultivation ponds are assumed sufficient to treat the wastewater for both BOD and nutrients to requisite levels in the discharge water (this requires research/operational data to validate). In this WWTP process, preliminary treatment (screens, grit removal, and grinders) and primary clarification steps are maintained. The sludge from primary clarification is then dewatered and sent for disposal while the primary effluent is routed to the open ponds for algae cultivation. Because the valorization method applied in this scenario assumes that the entire wastewater facility is replaced with an algae farm (with the exception of preliminary treatment/primary clarification), the AD unit is also assumed to be removed, as a redesign of municipal wastewater solids $\mathrm{AD}$ (configured to be integrated with clarified effluent algae treatment) is outside the scope of this work.

Similar to previous algae designs [2], cultivation productivity is set at a target annual average of $25 \mathrm{~g} / \mathrm{m}^{2} /$ day (ash-free dry weight [AFDW] algal biomass). However, in previous design targets for traditional algae farms, the seasonal variability was assumed to range from 3:1 between winter versus summer seasons. This range may reasonably be expected to be lower for a mixotrophic system, which utilizes organic carbon in the wastewater (thus diminishing an 
exclusive reliance on photosynthesis to cultivate algae, which becomes more limited in winter months with less solar irradiance). Moreover, recent state-of-technology data for traditional cultivation has demonstrated a lower seasonal variability of $2: 1$ [8], and therefore we used this $2: 1$ basis as an important parameter in setting the algae farm footprint for treating a constant flow of wastewater (assumed to be unchanged throughout the year). In previous designs, the algae facility size was fixed at 5,000 cultivation acres. Instead, here the flow of the WWTP is fixed with the algae facility size varying to use all nutrients ( $\mathrm{N}$ and $\mathrm{P}$ ) during the lowest productivity season for a set algae composition (shown at the bottom of Figures 6 and 7); however, in practice it is noted that it would be more cost-effective to only target nutrient uptake to the point of reaching discharge permits.

Two algae compositions are evaluated as reflected in Table 1, namely high-protein and highcarbohydrate Scenedesmus (HPSD and HCSD), to understand tradeoffs in overall biomass nutrient demands/uptake potential and their effect on algae farm size and economics [2]. However, in the context of this analysis, the HCSD basis is not likely to be realistic, as such an improved compositional quality is not typically consistent with polycultures of algal and bacterial/other biomass grown mixotrophically under high chemical oxygen demand (COD)/BOD. Even for the tertiary treatment scenario, which at least would be more exclusively algal biomass after organics are removed, achieving an HCSD-type composition would require longer hydraulic residence times and some degree of nutrient deprivation, which is counter to the objective of maximizing nutrient mitigation and water throughputs. Thus, the HPSD composition is generally a more relevant basis for both valorization methods, and although it does not fit well into NREL's prior CAP designs (focused on carbohydrates and lipids), it is pertinent to other conversion methods as well as future NREL work moving forward that will seek to focus more on higher-protein conversion options. Biomass is harvested at a constant density of $0.5 \mathrm{~g} / \mathrm{L}$, set by varying the removal rate of treated water (normally referred to as "blowdown" in traditional algae farm models seeking to minimize water footprint) to meet this parameter. Consistent with prior models, harvested biomass is dewatered through a three-stage process via gravity settling, a membrane filtration unit, and a centrifuge to reach a concentration of $20 \mathrm{wt} \%$ solids $[2,9]$.

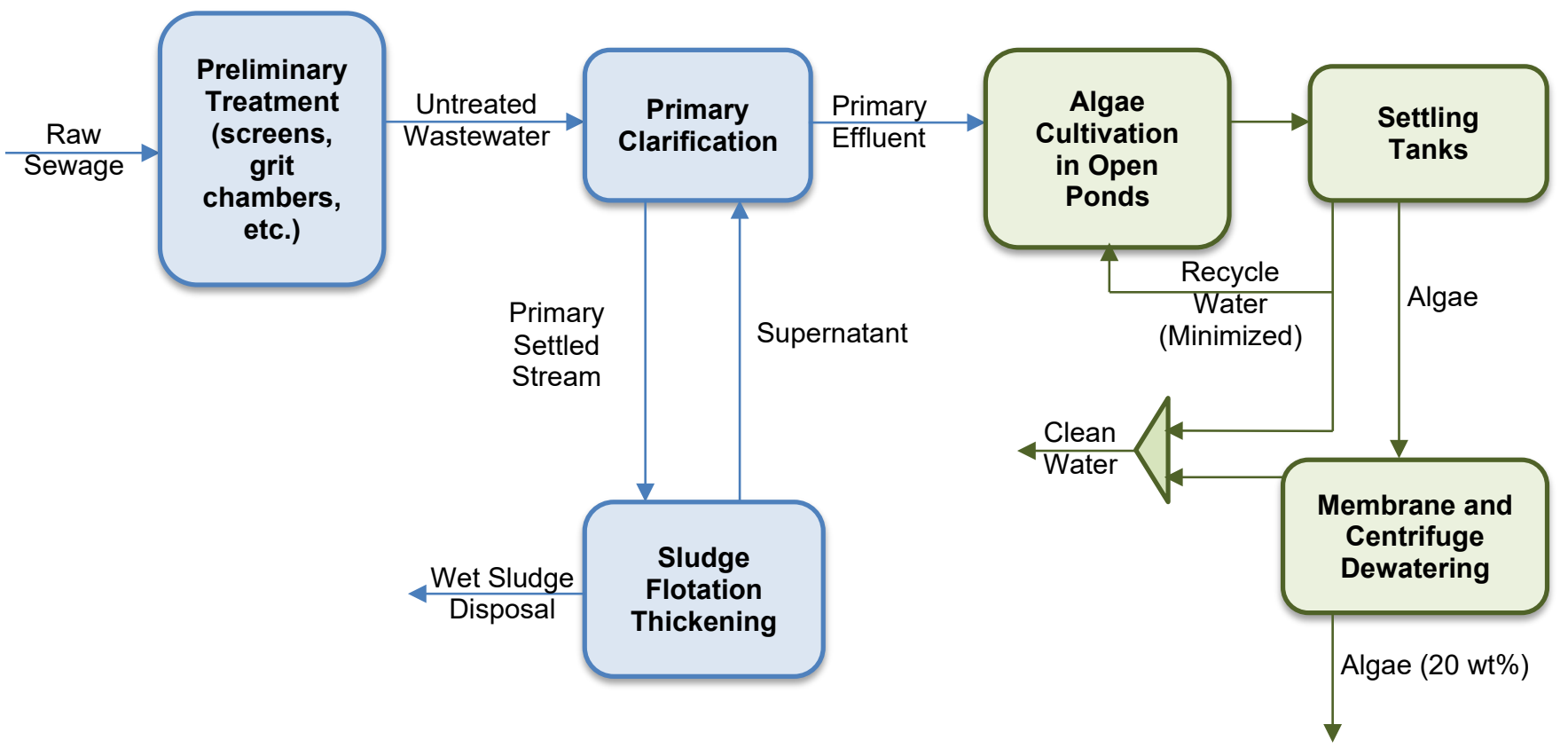

Figure 2. Block-flow diagram of WWT with algae cultivation (complete WWTP system) 
Table 1. Algae Composition for High-Protein Scenedesmus (HPSD) and

High-Carbohydrate Scenedesmus (HCSD) Scenarios Evaluated Here [2]

\begin{tabular}{|c|c|c|}
\hline $\begin{array}{c}\text { Wt\% composition } \\
\text { (AFDW basis) }\end{array}$ & HPSD & HCSD \\
\hline C & 52.2 & 54.0 \\
\hline $\mathrm{H}$ & 7.5 & 8.2 \\
\hline$N$ & 8.8 & 1.8 \\
\hline O & 30.4 & 35.5 \\
\hline$S$ & 0.0 & 0.2 \\
\hline $\mathrm{P}$ & 1.03 & 0.22 \\
\hline Total & 100.0 & 100.0 \\
\hline
\end{tabular}

The incoming wastewater stream is assumed at a base case flow of 10 million gallons per day (MGD) with N content of $36 \mathrm{mg} / \mathrm{L}, \mathrm{P}$ content of $8 \mathrm{mg} / \mathrm{L}$, and a COD of $750 \mathrm{mg} / \mathrm{L}$ (shown in Table 2) based on average data of WWT facilities greater than 1 MGD in the United States [10]. From this basis, the waste sludge disposal stream was estimated at 0.1 MGD (1\% of raw incoming wastewater flow), with associated COD, $\mathrm{N}$, and P loadings shown in Table 2 based on a literature search for typical waste sludge characteristics [11-14,7,15-17]. The primary effluent flow and nutrient loadings were then calculated based on mass balance between the wastewater feed and waste sludge disposal streams. Given a fixed flowrate and nutrient concentration in the resulting primary effluent stream (i.e., g/day of $\mathrm{N}$ and $\mathrm{P}$ available), the algae farm footprint size was then determined based on the targeted $25 \mathrm{~g} / \mathrm{m}^{2} /$ day cultivation productivity coupled with the biomass elemental composition in Table 1 (i.e., $\mathrm{g} / \mathrm{m}^{2} /$ day uptake rate demands for $\mathrm{C}, \mathrm{N}$, and $\mathrm{P}$ ) based on the lowest-productivity winter basis, with supplemental nutrients supplied at additional cost for higher-productivity periods. Without more detailed information around the balance between autotrophic versus heterotrophic modes of growth (utilizing inorganic $\mathrm{CO}_{2}$ versus organic wastewater carbon respectively), this preliminary assessment assumed that half of the requisite carbon is supplied through wastewater $\mathrm{COD}$, thereby reducing purchased $\mathrm{CO}_{2}$ costs by $50 \%$ relative to a purely photo-autotrophic cultivation model. (A sensitivity analysis was run to evaluate the impacts around this assumption, as presented later.)

All algae farm capital costs were maintained consistently with those presented in the algae farm design report (on a per-acre cultivation basis), with labor costs adjusted based on reasonable expectations of how each FTE position (number of employees) may change for differing algae farm footprint sizes relative to the original baseline at 5,000 acres of production cultivation area [2]. Finally, to valorize the treated wastewater (in this case viewing the wastewater as a coproduct and solving for biomass cost rather than vice-versa), a value was assigned at either $\$ 2,400 /$ million gallons ( $M G)$ or $\$ 4,500 / \mathrm{MG}$, as two possible scenarios to bracket the cost potential based on a wastewater industry report [18]. These cost values represent typical industry data for traditional WWTP operations and maintenance (O\&M) costs and for fully-burdened facility treatment costs including capital (passed to a consumer's service charges), respectively, indicating the "avoided expenses" for treating wastewater via algal cultivation rather than building and operating a new traditional WWTP [18]. Based on discussions with expert consultants in this field, MicroBio Engineering, this approach is also consistent with how they approach algal wastewater TEA [19]. 
Table 2. Flow Rates, Nutrient, and Carbon Content of Pertinent

Wastewater Streams Assumed in Present Work

\begin{tabular}{lccc}
\hline & $\begin{array}{c}\text { Raw Sewage } \\
{[10]}\end{array}$ & $\begin{array}{c}\text { Waste Sludge } \\
\text { Stream [11] [12] [13] } \\
{[14][7][15][16][17]}\end{array}$ & $\begin{array}{c}\text { Primary Effluent } \\
\text { (calculated by } \\
\text { difference) }\end{array}$ \\
\hline Flow (MGD) & 10 & 0.1 & 9.9 \\
Total P (mg/L) & 8 & 66 & 7 \\
Total N (mg/L) & 36 & 418 & 32 \\
COD (mg/L) & 750 & 5655 & 700 \\
\hline
\end{tabular}

\section{Valorization Method 2: Tertiary Treatment (N/P Removal)}

In the second integration point considered here for algal WWT, the WWTP maintains all standard operations leading to the secondary clarification step, with algal cultivation taking place subsequently utilizing the secondary clarification effluent. Again, while the characteristics of secondary effluent streams vary according to each respective WWT facility, the present work assumes a concentration of $0.9 \mathrm{mg} / \mathrm{L}$ total $\mathrm{P}$ and $5.8 \mathrm{mg} / \mathrm{L}$ total $\mathrm{N}$ (deduced from information published by the U.S. Environmental Protection Agency [EPA] in 2015) [10], relative to recent regulations that, in some instances, have become more stringent, down to discharge limits to less than $1 \mathrm{mg} / \mathrm{L}$ (limits for P are lower than those for $\mathrm{N}$ ) [10,5]. Based on discussions with private industry stakeholders, the incremental costs for treating water down to such stringent levels through traditional methods can be quite costly, with one comment from other collaborators (Neochloris and University of Illinois) noting over an order of magnitude higher costs per kg of $\mathrm{N}$ and P removed for such "deep" removal relative to standard ("bulk") WWT occurring upstream of the secondary clarification step [20]. Again, this challenge for the WWT industry thus represents an opportunity for algae, if algal cultivation systems could be designed and operated to achieve maximum N/P nutrient uptake while not contributing to toxins or extracellular dissolved organic carbon. As shown in Figure 3, under this scenario, the secondary clarification effluent is routed to algal cultivation and harvesting/dewatering, with the treated clean water effluent valued on a basis per-pound of $\mathrm{N}$ and $\mathrm{P}$ removed as discussed below. 


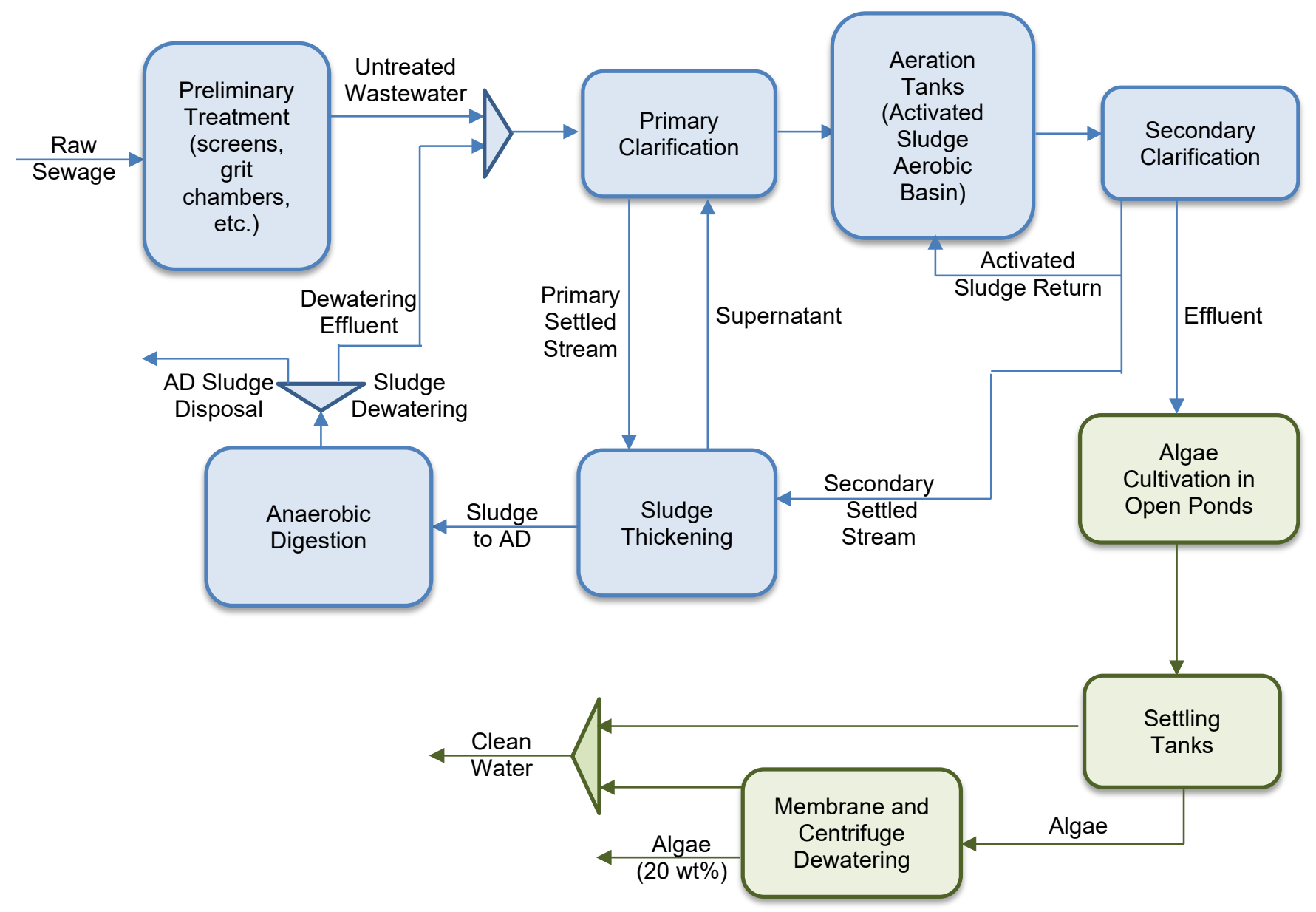

Figure 3. Block-flow diagram of WWT with algae cultivation (tertiary treatment for N/P removal)

Again, in this scenario, algal cultivation productivity was set at the targeted $25 \mathrm{~g} / \mathrm{m}^{2} /$ day annual average (AFDW) and 2:1 seasonal variability in the base case, evaluated across both HPSD and HCSD elemental compositions and associated nutrient demands, with the farm footprint size set based on wintertime production rates matching to all available N/P flows from secondary treatment $[8,2]$. Also, similar to the complete WWT case, this approach considers two levels for valorizing residual $\mathrm{N} / \mathrm{P}$ removal. Table 3 provides the $\mathrm{N}$ and $\mathrm{P}$ levels as may be encountered in raw sewage, and the nutrients assumed here to be remaining in the secondary effluent stream after most of the carbon and nutrients have been treated by upstream WWT operations. Unlike the values in Table 2, the secondary effluent is assumed to have no measurable COD by that point and the remaining total $\mathrm{P}$ is a magnitude lower than the primary effluent stream, reducing from $7 \mathrm{mg} / \mathrm{L}$ to $0.9 \mathrm{mg} / \mathrm{L}$ [10]. The secondary effluent also contains $5.8 \mathrm{mg} / \mathrm{L}$ of total $\mathrm{N}$ compared to $32 \mathrm{mg} / \mathrm{L}$ in the primary effluent [10]. Although these secondary N/P levels were deduced from the above-cited EPA reference, in practice these values may be lower than those typically encountered for secondary effluent today (further discussions with industry collaborators following completion of this report have indicated higher levels more typically in a range of $15-25 \mathrm{mg} / \mathrm{L}$ total $\mathrm{N}$ and $3-5 \mathrm{mg} / \mathrm{L}$ total $\mathrm{P}$, though such values would further improve economics for N/P mitigation if starting at such higher levels for tertiary treatment compared to those presented here). With a smaller flow of nutrients to uptake, the farm footprint for this scenario is smaller than the footprint calculated for the complete WWT scenario. 
Table 3. Flow Rates and Nutrient Content of Pertinent Wastewater Streams Assumed in Present Work (Deduced from [10])

\begin{tabular}{lcc}
\hline & Raw Sewage & Secondary Effluent \\
\hline Flow (MGD) & 10 & 9.9 \\
Total P $(\mathrm{mg} / \mathrm{L})$ & 8.1 & 0.9 \\
Total N $(\mathrm{mg} / \mathrm{L})$ & 35.8 & 5.8 \\
COD $(\mathrm{mg} / \mathrm{L})$ & 750 & 0 \\
\hline
\end{tabular}

The valorization method under this scenario reflects mitigation costs that are associated with traditional technologies to reduce $\mathrm{N}$ and $\mathrm{P}$, with this study targeting maximal algal uptake achieving near-complete removal to less than $0.1 \mathrm{mg} / \mathrm{L}$ in the discharge water. In a report by the EPA, several hundred WWT facilities in the United States were surveyed for N and P influent levels, effluent levels, and the corresponding capital and operating costs to reach those effluent levels. Figure 4 shows the results of that survey calculated based on the $\$ / 1 \mathrm{~b}$ cost to remove $\mathrm{N}$ and $\mathrm{P}$ and the associated concentration for $\mathrm{N}$ and $\mathrm{P}$ in the effluent. On average, the cost to remove $\mathrm{N}$ and $\mathrm{P}$ is $\$ 4.50 / \mathrm{lb}(2012 \$)$ down until a concentration of $\sim 1 \mathrm{mg} / \mathrm{L}$ [10]. Beyond this threshold, removing more $\mathrm{N}$ and $\mathrm{P}$ cannot be done with conventional methods and requires a tertiary treatment at much higher cost. For example, to remove $P$ from $1 \mathrm{mg} / \mathrm{L}$ to $0.1 \mathrm{mg} / \mathrm{L} \mathrm{a}$ process using activated ferrous metals is employed [5]. Another report examines the capital and operating costs for WWTPs that reduce N and P levels to $0.1 \mathrm{mg} / \mathrm{L}$. Of the $80 \mathrm{WWTP}$ surveyed, 26 have a capacity greater than 0.5 MGD and are shown in Figure 5 [5]. Although more scattered in the cost of removal because of the various methods employed, the average cost of removal is $\$ 67.4 /$ lb of $\mathrm{N}$ or $\mathrm{P}(2012 \$)$, which is over 10 times greater than the less stringent nutrient removal methods to higher concentrations, reaching up to $\$ 100 / \mathrm{lb}$ or more of $\mathrm{N}$ or $\mathrm{P}$ removal.

In this assessment, the secondary effluent containing $0.9 \mathrm{mg} / \mathrm{L}$ of $\mathrm{P}$ and $5.8 \mathrm{mg} / \mathrm{L}$ of $\mathrm{N}$ is integrated with the algae farm such that all nutrients are assumed to be completely removed by the algae along with supplementary nutrients fed to the process during higher-productivity seasons beyond winter. No carbon is assumed to be present, so all carbon for algal growth in this case is derived from supplemental $\mathrm{CO}_{2}$. Based on the above information, reducing the secondary effluent $\mathrm{N}$ levels from $5.8 \mathrm{mg} / \mathrm{L}$ to $1 \mathrm{mg} / \mathrm{L}$ first yields a coproduct credit of $\$ 4.50 / \mathrm{lb}$ for $\mathrm{N}$ removed (2012\$) in the present TEA estimates [10]. Further reducing the remaining $\mathrm{N}$ and $\mathrm{P}$ (1 $\mathrm{mg} / \mathrm{L}$ and $0.9 \mathrm{mg} / \mathrm{L}$, respectively) to $0.1 \mathrm{mg} / \mathrm{L}$ yields an additional coproduct credit of $\$ 67.40 / \mathrm{lb}$ for $\mathrm{N}$ or $\mathrm{P}$ removed, with a "high" coproduct value of $\$ 100 / \mathrm{lb}$ for $\mathrm{N}$ or $\mathrm{P}$ removed also alternatively considered [5]. While this study lumps $\mathrm{N}$ and $\mathrm{P}$ treatment credits together based on somewhat sparse availability of the data, in reality, feedback from industry has indicated that $\mathrm{P}$ removal is significantly more costly (and thus valuable for algae treatment) than $\mathrm{N}$ removal. Future work will revisit the assumptions made in this assessment regarding influent/effluent concentrations as well as individual N/P treatment credits in further granularity. 


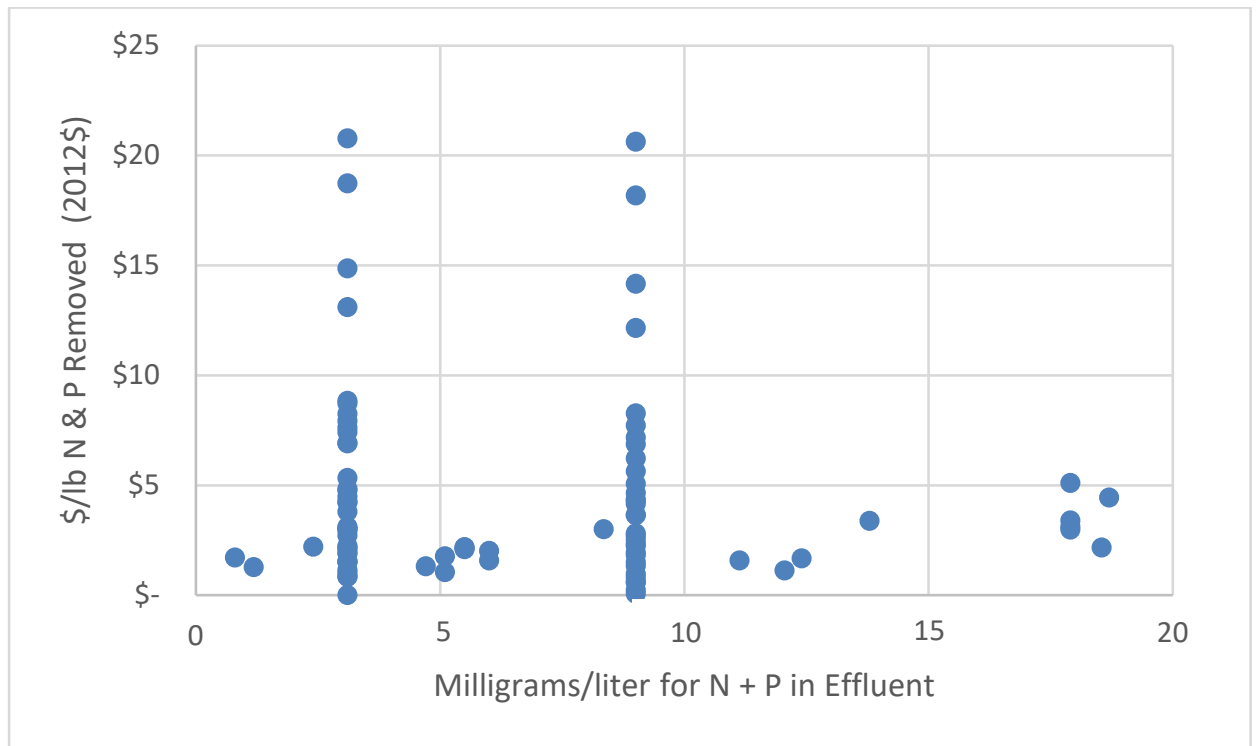

Figure 4. Industry survey costs for reducing high concentration $\mathrm{N}$ and $\mathrm{P}$ to $\sim 1 \mathrm{mg} / \mathrm{L}[10]$

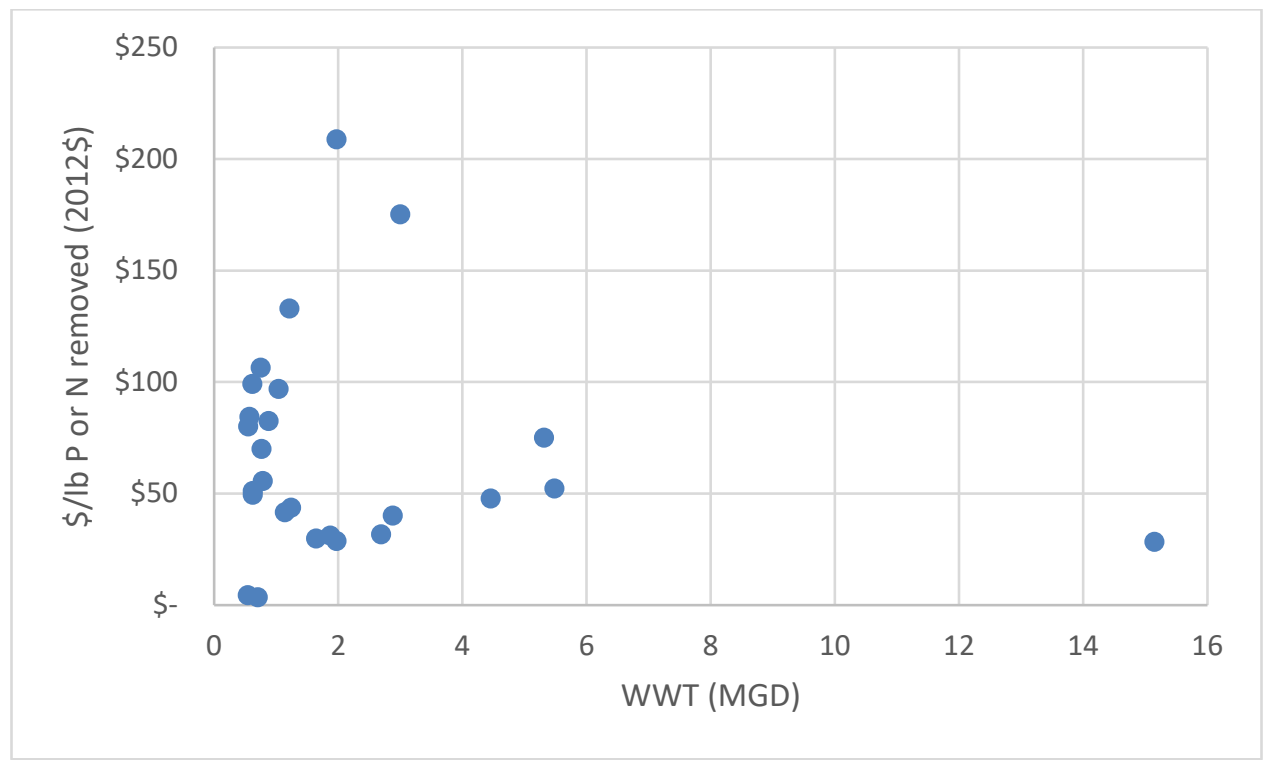

Figure 5. Industry survey costs for reducing $N$ and $P$ concentration from $1 \mathrm{mg} / \mathrm{L}$ to $0.1 \mathrm{mg} / \mathrm{L}$ vs. WWT size [5] 


\section{Results and Discussion}

\section{Valorization Method 1: Complete WWTP}

The resulting minimum biomass selling price (MBSP) for the first case (complete WWT replacement) is shown in Figure 6, reflecting eight total scenarios investigated for this approach. Relative to "traditional" algal cultivation using local water resources and externally purchased $\mathrm{N}$, $\mathrm{P}$, and $\mathrm{CO}_{2}$ at a targeted MBSP of $\$ 488 /$ ton AFDW based on the HCSD target biomass composition, the MBSP for complete algal WWT would reduce to $\$ 326 /$ ton or $\$ 237 /$ ton for WWT credits of $\$ 2,400 / \mathrm{MG}$ and $\$ 4,500 / \mathrm{MG}$ respectively (all results are in 2016 dollars with a $21 \%$ tax rate). As discussed above, recognizing that an HCSD-type composition would likely be difficult to achieve in this context when algae is continuously produced to uptake a continuous feed of nutrients, a high-nitrogen HPSD biomass compositional basis would likely be more relevant for this situation. In that case, MBSPs would drop substantially to $\$ 108 /$ ton for the $\$ 2,400 / \mathrm{MG}$ credit, or to negative $\$ 311 /$ ton for the $\$ 4,500 / \mathrm{MG}$ credit. This is because the water treatment credits are the same (in all cases treating $10 \mathrm{MGD}$ at a fixed treatment credit), but require substantially less cultivation area and associated expenses to consume all nutrients; however, they also produce substantially less biomass at nearly fivefold higher $\mathrm{N}$ and $\mathrm{P}$ content for HPSD versus HCSD (see Table 1).

Given the finding of significantly lower biomass costs for HPSD than HCSD compositions (as well as the fact that HPSD is more realistic for this particular context as noted above), additional scenarios were also investigated for the "complete WWT" approach, but were limited only to HPSD compositions. Namely, as shown in the right half of Figure 6, increasing the facility scale from treating $10 \mathrm{MGD}$ to $50 \mathrm{MGD}$ (representing the largest wastewater facilities in the United States, which account for less than 3\% of total WWT facilities) would lead to marginal further cost savings on the order of roughly $\$ 80 /$ ton, at MBSPs of $\$ 23 /$ ton or negative $\$ 396 /$ ton for the $\$ 2,400 / \mathrm{MG}$ and $\$ 4,500 / \mathrm{MG}$ credits, respectively. Thus, co-locating algae farms with WWTPs does not necessarily require being limited to only very large WWTP scales. Additionally, reducing the annual variability in cultivation productivity from the $2: 1$ base case down to a hypothetical 1:1 basis (eliminating seasonal variability completely) translates to dramatic MBSP savings, reducing the MBSP from $\$ 23 /$ ton to negative $\$ 288 /$ ton for the $\$ 2,400 / \mathrm{MG}$ WWT credit basis, or from negative \$396/ton to negative \$976/ton for the \$4,500/MG WWT credit basis. This is attributed to the elimination of all equipment over-design, plus full utilization of the wastewater nutrients in all seasons without the need for adding further supplemental nutrients at additional cost when seasonal biomass productivity increases. As a sensitivity to the assumed $50 \% \mathrm{CO}_{2}$ reduction relative to fully autotrophic growth (with the remaining $50 \%$ of required carbon assumed to be met through the organic COD content in the wastewater influent), the MBSP for all cases would increase universally by $\$ 50 /$ ton if all carbon demands were met through $100 \%$ purchased $\mathrm{CO}_{2}$.

While these scenarios for algal WWT offer clear TEA cost advantages relative to traditional algal cultivation, the other important factor to understand is the national scalability for this approach, being limited to co-location with finite WWT facilities. The right axis in Figure 6 presents the algal biomass yield per volume of wastewater treated, based on the underlying $\mathrm{N}$ and $\mathrm{P}$ content (demand) of the biomass. The figure highlights that, although the HPSD composition cases offer significant cost advantages over the HCSD composition, the HPSD biomass yield is nearly fivefold lower per volume of wastewater treated (tied to the nearly fivefold higher $\mathrm{N}$ and $\mathrm{P}$ content in the biomass). The bottom table of Figure 6 presents resulting 
estimates for national-scale algal biomass and biofuel potential tied to each individual scenario, with the potential shown for both a "base case" and "high case." The valorization method taken in the TEA for the complete WWT scenario implicitly assumes that an algae farm is built instead of a traditional WWT facility (based on the \$/MM gallon avoided costs attributed to traditional WWT facilities as noted above), and thus would not be fair to consider the entire existing national WWT capacity of 34.5 billion gallons per day (BGD) for purposes of calculating the associated algal biomass production potential (as this would assume that new algae WWT farms are built to handle wastewater already being treated by existing WWT facilities while also claiming the cost credit for avoided WWT construction/operation expenses). Instead, such a valorization approach is more appropriately applied for future resource potential where there would be a binary option to build a new traditional WWT facility or a new algae farm.

As a preliminary estimate, new future incremental wastewater capacity was estimated by scaling the existing capacity (34.5 BGD) by the projected U.S. population growth through 2050 (398 versus 321 million people, or a $25 \%$ population growth relative to 2015) as a reasonable proxy for generated wastewater volumes. A 25\% growth over 34.5 BGD translates to 8.6 BGD of incremental new wastewater volume that must be treated in excess of existing WWT facility infrastructure. For "base case" biomass potential calculations, we assume that $50 \%$ of this 8.6 BGD will be available to be treated nationally via algal cultivation, between location constraints imposed by latitude (with more northern latitudes less likely to be suitable for algal cultivation particularly in open ponds) and by land availability (recognizing WWT facilities are typically located in densely populated areas where large amounts of unoccupied land are not always available as required for algae farms). With this basis, the resulting national biomass potential would be roughly $29 \mathrm{MM}$ tons/yr for the HCSD cases shown in Figure 6, dropping to $6 \mathrm{MM}$ tons/yr for the HPSD cases and then further to 4 MM tons/yr for HPSD on a 1:1 seasonal variability (the lowest MBSP cases). At a targeted $84 \mathrm{GGE} /$ ton fuel yield consistent with achievable CAP processing targets, this would translate to 2.5 billion GGE/yr (BGGE/yr) for the HCSD cases, reducing to $0.5 \mathrm{BGGE} / \mathrm{yr}$ for HPSD or to $0.3 \mathrm{BGGE} / \mathrm{yr}$ for HPSD at the $1: 1$ seasonal variability basis. Yields are lower for the 1:1 seasonality case than for $2: 1$ because the only algae cultivated in the former case is that which can be grown on wastewater nutrients, while 2:1 seasonality produces more algae during higher-productivity seasons (at the expense of supplemental fertilizer nutrient purchase). While this could translate to a reasonable "base case" biomass/biofuel potential for the HCSD composition basis, this potential is considerably smaller for a more realistic HPSD composition in this context.

Alternatively, the "high case" potential calculations shown in Figure 6 assume the total available wastewater volume is doubled (back to 8.6 BGD), which may for example reflect a $25 \%$ replacement of the existing (aging) 34.5-BGD WWT facility capacity by 2050, again half of which could be assumed to be available for algal cultivation (i.e., an additional 4.3 BGD). Under this scenario, the national biomass/biofuel potential output would be twice the base case, up to roughly $5 \mathrm{BGGE} / \mathrm{yr}$ fuels for HCSD, $1 \mathrm{BGGE} / \mathrm{yr}$ for HPSD, or 0.6 BGGE/yr for HPSD at a 1:1 cultivation variability. However, it should be noted that this likely errs on the optimistic/high side as none of these resource calculations consider other details such as supplemental $\mathrm{CO}_{2}$ availability or potential financial incentives to sell algal biomass at a price higher than the MBSP. As an additional sensitivity case, if the fourth scenario in Figure 6 (HPSD, 10 MGD, $\$ 4,500 / \mathrm{MG}$ credit) increased the basis farm size from 470 to 1,000 acres, thereby requiring import of supplemental fertilizer nutrients during all seasons (including winter), the MBSP would increase to $\$ 163 /$ ton (rather than negative $\$ 311 /$ ton) but yield would also increase significantly to $13.2 \mathrm{MM}$ tons/yr in the base case (roughly $1.1 \mathrm{BGGE} / \mathrm{yr}$ ). 


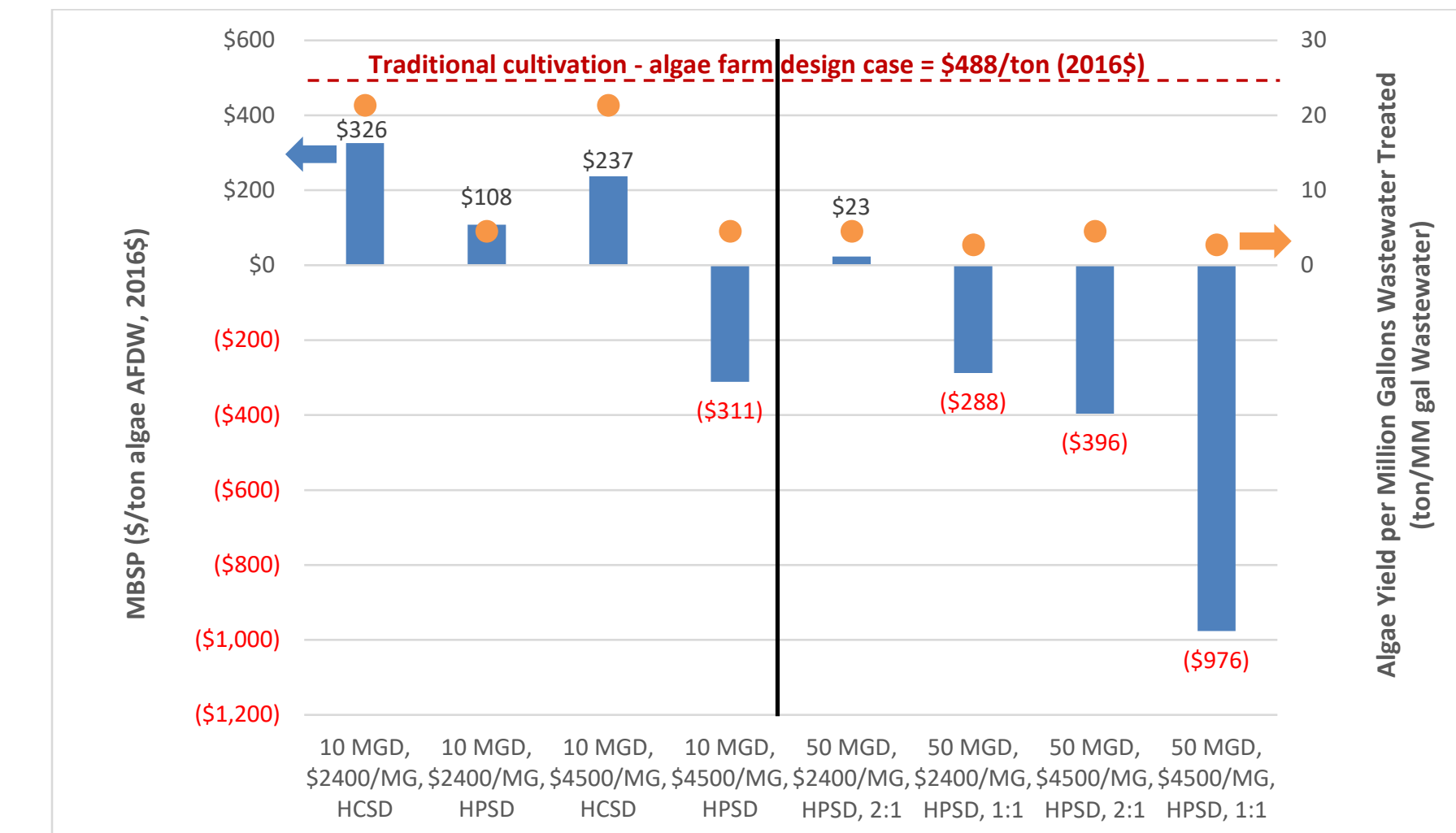

\begin{tabular}{|l|c|c|c|c|c|c|c|c|}
\hline $\begin{array}{l}\text { Algal biomass potential, } \\
\text { MM tons/yr (base) }\end{array}$ & 29.2 & 6.2 & 29.2 & 6.2 & 6.2 & 3.8 & 6.2 & 3.8 \\
\hline $\begin{array}{l}\text { Algal biofuel potential, } \\
\text { BGGE/yr (base) }\end{array}$ & 2.5 & 0.5 & 2.5 & 0.5 & 0.5 & 0.3 & 0.5 & 0.3 \\
\hline $\begin{array}{l}\text { Algal biomass potential, } \\
\text { MM tons/yr (high) }\end{array}$ & 58.4 & 12.4 & 58.4 & 12.4 & 12.4 & 7.5 & 12.4 & 7.5 \\
\hline $\begin{array}{l}\text { Algal biofuel potential, } \\
\text { BGGE/yr (high) }\end{array}$ & 4.9 & 1.0 & 4.9 & 1.0 & 1.0 & 0.6 & 1.0 & 0.6 \\
\hline Algae farm size (acres) & 2150 & 470 & 2150 & 470 & 2353 & 1473 & 2353 & 1473 \\
\hline
\end{tabular}

The blue bars represent the MBSP calculated using our standard TEA methodologies (left axis), while the orange dots represent the biomass yield per million gallons of wastewater processed (right axis). Lower table provides the algal biomass and biofuel potential for a base and "high" case corresponding to each scenario in the plot.

Figure 6. TEA results and national resource potential for scenarios considered under Case 1: Complete WWT

\section{Valorization Method 2: Tertiary Treatment (N/P Removal)}

For the second WWT integration approach (tertiary treatment), 10 total scenarios were examined with results shown in Figure 7. Compared to the "traditional" cultivation farm model at a targeted \$488/ton MBSP for an HCSD-equivalent algae composition, assuming the same HCSD basis and N/P remediation credits of $\$ 67 / \mathrm{lb}$ (for the "maximum" removal levels between $1 \mathrm{mg} / \mathrm{L}$ to $0.1 \mathrm{mg} / \mathrm{L}$ ), the MBSP is reduced by $\$ 389 /$ ton down to $\$ 99 /$ ton. For the upper N/P remediation credit value of $\$ 100 / \mathrm{lb}$, the MBSP would become highly profitable at negative $\$ 112 /$ ton.

However, as discussed above, in this context of continuous remediation of influent $\mathrm{N}$ and $\mathrm{P}$, the HCSD composition basis is likely less realistic, whereas the HPSD composition would support higher pond turnover and continuous nutrient uptake associated with a higher $\mathrm{N}$ and $\mathrm{P}$ content in the biomass (although at least in the tertiary treatment scenario the cultivated biomass would largely be algae, and thus have a better chance of approaching an HCSD-type composition). 
Again like the prior case, when moving from HCSD to HPSD compositions, there is a large benefit in reduced facility footprint and associated costs needed to consume the nutrients (albeit at lower biomass yield). For example, the HPSD composition at $\$ 67 / \mathrm{lb} \mathrm{N}$ and $\mathrm{P}$ and $\$ 100 / \mathrm{lb} \mathrm{N}$ and $\mathrm{P}$ credits translates to MBSPs of negative $\$ 1,599 /$ ton and negative $\$ 3,013 /$ ton, respectively.

Consistent with the cases examined by the complete WWT scenario, the seasonal variability of cultivation productivity was evaluated down to a 1:1 basis (no variability). However, as the secondary effluent stream does not contain accessible carbon for mixotrophic growth, which somewhat helps to offset seasonal swings for purely autotrophic growth (assuming a larger driver behind seasonal variability comes from photosynthetic irradiance than from temperature swings), eliminating seasonal variability completely is unlikely to be achieved unless a more controlled closed PBR system is employed, possibly including some degree of artificial illumination, similar to designs being pursued in industry. Still, under the 1:1 variability basis for HPSD, the MBSP could hypothetically be reduced to negative $\$ 1,963 /$ ton and negative $\$ 3,594 /$ ton, for the $\$ 67 / \mathrm{lb}$ and $\$ 100 / \mathrm{lb} \mathrm{N}$ and $\mathrm{P}$ credit cases, respectively. Such a large cost offset could potentially justify the added expense for such a controlled PBR design. Finally, increasing the scale to accommodate larger 50 MGD WWT capacities would again lead to additional MBSP reductions, with the cases evaluated in Figure 7 ranging from negative $\$ 2,348 /$ ton to negative $\$ 4,433 /$ ton. In addition to the eight cases above, we also examined several cases where the harvest density was set at $0.5 \mathrm{~g} / \mathrm{L}$ through algae recycle. When a fraction of the stream after harvesting and concentration is recycled back to the ponds, the net harvested biomass concentration is increased but more algae is also lost to blowdown. Under that approach, the higher harvest density design still proved highly profitable (negative MBSPs, although slightly less negative than the cases shown in Figure 7) for all HPSD scenarios.

In addition to the cost and yield results, the corresponding table at the bottom of Figure 7 again provides the estimated algae biomass potential (MM tons/yr) and biofuel potential (BGGE/yr) for a base and target case. For this scenario, the base case potential assumes that $50 \%$ of the existing 34.5-BGD WWT capacity in the United States could be integrated with tertiary algal treatment. Unlike the complete WWT approach, the tertiary treatment approach is not necessarily constrained only to new incremental WWT capacity (or replacement of retired WWT facilities), as it largely represents a new opportunity to add further WWT capabilities onto the end of existing operations (assuming that the majority are not yet otherwise configured to meet more stringent N/P discharge limits), thus the resource potential may more directly tap into current wastewater volumes. However, similar to the arguments discussed for the complete WWT case, the "base case" here limits the national resource potential to $50 \%$ of the full 34.5 -BGD capacity, to provide allowances for location constraints (latitude, available land around population centers, etc.) as well as acknowledging that some WWT facilities will already be able to meet stringent discharge levels without a need for tertiary treatment or with existing equipment already in place. For a "high case," an additional $50 \%$ of projected future incremental additional capacity is added to the base case using the same population growth figure discussed in the complete WWT scenario (roughly $25 \%$ growth by 2050 ), assuming that $50 \%$ of total future wastewater capacity may leverage tertiary algal treatment. In all the HCSD cases, the biomass potential is estimated at 12.3 up to $15.3 \mathrm{MM}$ tons/yr, translating to a biofuel potential of $1.0 \mathrm{BGGE} / \mathrm{yr}$ and 1.3 $\mathrm{BGGE} / \mathrm{yr}$ for the base and high cases, respectively. For all HPSD cases with a 2:1 seasonality ratio, the base and high biomass potential is 1.8 and $2.3 \mathrm{MM}$ tons/yr, respectively, translating to a fuel potential of 0.15 to $0.19 \mathrm{BGGE} / \mathrm{yr}$. Finally, for the HPSD cases with a $1: 1$ seasonality ratio, the biomass potential drops to 1.6 and 2.0 $\mathrm{MM}$ tons/yr for the base and high cases, respectively, translating to a fuel potential of roughly 0.13 to $0.17 \mathrm{BGGE} / \mathrm{yr}$. 
Finally, it is also worth noting that although national-scale algal biomass/biofuel potential may be somewhat limited when coupled to municipal wastewater capacity as projected here, similar opportunities for algae may exist for other waste resources of comparable or larger volumes. For example, animal manure accounts for over fortyfold higher annual waste production by dry mass compared to human sewage generation in the United States [21], accounting for significant groundwater contamination and runoff issues. If such material could first be treated to reduce organic content, e.g., via anaerobic digestion, hydrothermal liquefaction, or other means, the resulting aqueous streams containing high $\mathrm{N} / \mathrm{P}$ levels could be processed through similar algal remediation approaches as those considered here for municipal wastewater [20], thereby unlocking substantially higher algal biomass production potential while addressing key environmental challenges in a more sustainable way.

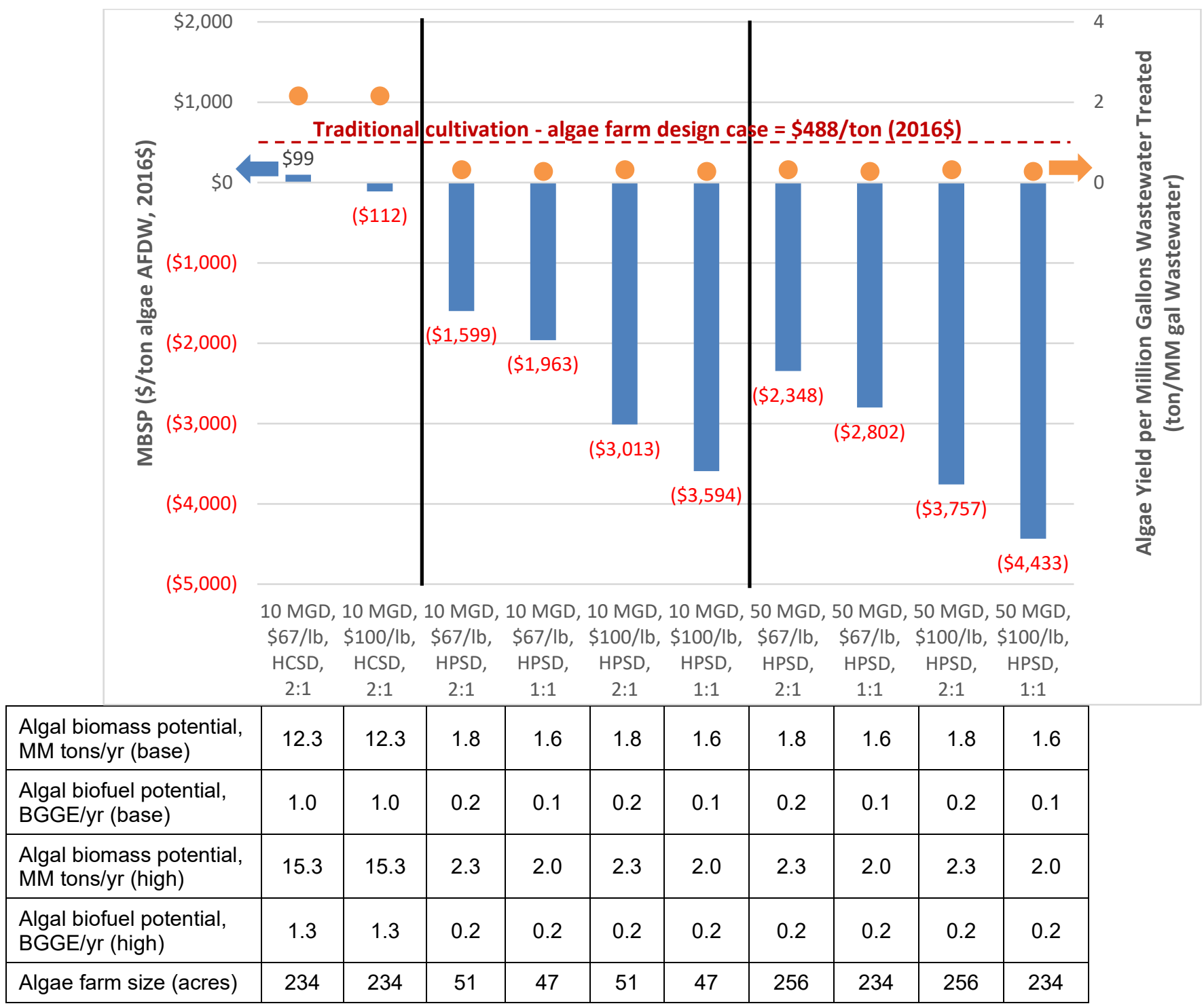

The blue bars represent the MBSP calculated using our standard TEA methodologies (left axis), while the orange dots represent the biomass yield per million gallons of wastewater processed (right axis). Lower table provides the algal biomass and biofuel potential for a base and "high" case corresponding to each scenario in the plot.

Figure 7. TEA results and national resource potential for scenarios considered under Case 2: Tertiary Treatment for N/P Removal 


\section{Concluding Remarks}

In this exercise, we examined high-level TEA implications for using algae to treat wastewater, examined from the standpoint of the algae farm (valorizing wastewater remediation as a coproduct revenue stream for the algae farm to reduce biomass selling prices). Under the first scenario considered as "complete" WWT, the algae farm was assumed to be built instead of a new (or replaced) traditional WWT facility, following initial WWT pretreatment steps. Under this approach, water treatment coproduct credits were assigned based on a dollar-per-milliongallon throughput basis, reflecting industry data for traditional O\&M costs alone or for fully burdened WWT construction and operation costs, crediting the same treatment costs to the algae farm as an "avoided expense." Under our standard lower-protein HCSD biomass composition basis, the resulting MBSPs were considerably reduced from the established algae farm design case targets of $\$ 488 /$ ton, down to $\$ 326 /$ ton or $\$ 237 /$ ton AFDW depending on the valorization credit, which would provide significant assistance in enabling conversion fuel selling prices to achieve the $\$ 2.5 / \mathrm{GGE}$ targets with less reliance on coproducts; additionally, existing and future estimated wastewater volumes could plausibly support roughly 30-60 MM tons/yr of algal biomass at the national scale, translating to roughly $2.5-5 \mathrm{BGGE} / \mathrm{yr}$ of national fuel potential. However, this is a less realistic scenario in this particular context focused on continuous treatment of N/P loads in incoming wastewater while also achieving the targeted $25 \mathrm{~g} / \mathrm{m}^{2} /$ day cultivation productivity target. Alternatively, if focused on a higher-protein HPSD composition (and thus higher $\mathrm{N}$ and $\mathrm{P}$ content, which is more realistic in this application as it does not allow for "turning off" nutrient feeds to promote compositional shifts), the amount of biomass produced, and thus the algae farm size, is considerably reduced to match the required N/P uptake rates. This translates to lower MBSPs (\$108/ton to negative $\$ 311 /$ ton, which could reduce even further for larger WWT scales or reduced seasonal productivity variability), but also lower biomass production potential (roughly 4-12 MM tons/yr national biomass potential, translating to $0.3-1.0 \mathrm{BGGE} / \mathrm{yr}$ national fuel potential). In all cases, the assumed valorization credits between $\$ 2,400$ and $\$ 4,500 / \mathrm{MM}$ gallon represent a critical driver behind the overall economic viability for this approach.

The second integration scenario considered incorporating algae as a tertiary treatment method for enhanced N/P mitigation, where the algae farm would serve as an addition to support traditional WWT facilities' efforts to meet more stringent N/P discharge concentration goals (targeted here to be maximally reduced as low as $0.1 \mathrm{mg} / \mathrm{L}$, though future work will refine this to higher/more practical discharge limits reflecting current regulatory guidelines closer to $1 \mathrm{mg} / \mathrm{L} \mathrm{P}$ and higher levels for $\mathrm{N}$ ), as an alternative to other more traditional N/P mitigation options. Under this approach, treatment credits were assigned based on a fixed dollar-per-pound of $\mathrm{N}$ and $\mathrm{P}$ removal basis, based on values from literature and discussions with industry bracketing a lower and upper range of potential N/P removal credits (again viewed as "avoided expenses" that reflect costs for alternative competing technologies to achieve the same goal). Similar to the "complete WWT" scenario, the standard HCSD compositional basis was found to offer substantial MBSP reduction benefits relative to the established algae farm design case, with MBSPs reduced to $\$ 99 /$ ton or negative \$112/ton for the lower- and higher-value credits, respectively, while enabling roughly 12-15 MM tons/yr of national biomass potential (attributed to 1.0-1.3 BGGE/yr of national biofuel potential). Given similar issues with the HCSD compositional basis as noted above, the HPSD compositional basis would further reduce MBSPs to roughly negative $\$ 1,600$ to $\$ 3,000 /$ ton, which could again reduce further for either larger WWT volumes or reduced seasonal variability (more applicable to a controlled PBR system); but also would again translate to lower national scalability potential at $1.6-2.3 \mathrm{MM}$ tons/yr biomass or $0.1-0.2 \mathrm{BGGE} / \mathrm{yr}$ 
biofuel (less than $0.1 \%$ of U.S. annual transportation fuel consumption). Such large negative MBSPs, while not reflective of how a real facility would actually operate, indicate a highly profitable operation that does not rely on revenues from selling biomass to remain viable, thus adding credence to the assertions that highly engineered cultivation systems pursued by some in industry for handling tertiary wastewater may be plausible for use in this application.

In summary, given such large allowances for valorizing wastewater treatment, both integration approaches appear to offer the potential for strong economic favorability, with tertiary treatment offering even lower MBSPs (larger revenues per amount of biomass produced) than complete WWT. However, with the exception of lower $\mathrm{N}$ and $\mathrm{P}$ algal composition (HCSD-equivalent) cases, which would be less practical in this context, the national scalability for algal biomass and ultimately biofuels is fairly constrained when considered as an opportunity for algae to make meaningful contributions to national fuel production. While this may limit the relevance for broader fuel-scale adoption interest, it does not diminish the importance of this application to help meet challenging demands for wastewater treatment in a competitive or potentially more economical way compared to traditional WWT techniques, while supporting a nascent algae industry to begin developing learnings that could be applied to other algae systems in the future. Finally, although this exercise required placing a valorization credit on the treated water and solving for MBSP in order to provide more directly comparable results to our prior algae farm models (translating to very large coproduct revenues relative to biomass revenues), a more appropriate way to estimate the economics for this application as a stand-alone TEA assessment would be to assign a fixed sale price to the relatively small amount of biomass produced and solve for either wastewater treatment cost or for facility net present value. Such an approach may be further evaluated in the future, although more suitably from the viewpoint of comparing wastewater technology options rather than algae cultivation options. Future work will also revisit assumptions made here in further granularity regarding influent and targeted discharge N/P concentrations, as well as treatment credits tailored to each respective nutrient component. 


\section{References}

1. Davis, R., C. Kinchin, J. Markham, E. Tan, L.M.L. Laurens, D. Sexton, D. Knorr, P. Schoen, and J. Lukas. 2014. Process Design and Economics for the Conversion of Algal Biomass to Biofuels: Algal Biomass Fractionation to Lipid-and Carbohydrate-Derived Fuel Products. Golden, CO: National Renewable Energy Laboratory.

2. Davis, R., J. Markham, C. Kinchin, N. Grundl, E.C.D. Tan, and D. Humbird. 2016. Process Design and Economics for the Production of Algal Biomass: Algal Biomass Production in Open Pond Systems and Processing Through Dewatering for Downstream Conversion. Golden, CO: National Renewable Energy Laboratory.

3. Davis, R., J.N. Markham, C.M. Kinchin, C. Canter, J. Han, Q. Li, A. Coleman, S. Jones, M. Wigmosta, and Y. Zhu. 2018. 2017 Algae Harmonization Study: Evaluating the Potential for Future Algal Biofuel Costs, Sustainability, and Resource Assessment from Harmonized Modeling. Golden, CO: National Renewable Energy Laboratory.

4. $\quad$ Seiple, T.E., A.M. Coleman, and R.L. Skaggs. 2017. "Municipal wastewater sludge as a sustainable bioresource in the United States." Journal of Environmental Management 197: 673680 .

5. Tetra Tech Inc. 2014. Lake Champlain Phosphorus Removal: Technologies and Cost for Point Source Phosphorus Removal. Denver, CO: Tetra Tech Inc.

6. Lundquist, T.J., I.C. Woertz, N.W.T. Quinn, and J.R. Benemann. 2010. A Realistic Technology and Engineering Assessment of Algae Biofuel Production. Berkeley, CA: Energy Biosciences Institute.

7. Shi, C.Y. 2011. Mass Flow and Energy Efficiency of Municipal Wastewater Treatment Plants. London: IWA Publishing.

8. Davis, R., and J. Clippinger. 2018. Algae Biofuels Techno-Economic Analysis FY18 Q4 Milestone: 2018 State of Technology. Golden, CO: National Renewable Energy Laboratory.

9. Cai, H., J. Dunn, A. Pegallapati, Q. Li, C. Canter, E. Tan, M. Biddy, et al. 2017. Supply Chain Sustainability Analysis of Renewable Hydrocarbon Fuels via Indirect Liquefaction, Fast Pyrolysis, and Hydrothermal Liquefaction: Update of the 2016 State-of-Technology Cases and Design Cases. Lemont, IL: Argonne National Laboratory.

10. U.S. Environmental Protection Agency. 2015. A Compilation of Cost Data Associated with the Impacts and Control of Nutrient Pollution. Washington, DC: Office of Water, U.S. Environmental Protection Agency.

11. Bohutskyi, P., D.C. Kligerman, N. Byers, L.K. Nasr, C. Cua, S. Chow, C. Su, Y. Tang, M.J. Betenbaugh, and E.J. Bouwer. 2016. "Effects of inoculum size, light intensity, and dose of anaerobic digestion centrate on growth and productivity of Chlorella and Scenedesmus microalgae and their poly-culture in primary and secondary wastewater." Algal Research 19: 278-290. 
12. Zhou, Y., L.C. Schideman, G. Yu, and Y. Zhang. 2013. "A synergistic combination of algal wastewater treatment and hydrothermal biofuel production maximized by nutrient and carbon recycling." Energy \& Environmental Science 6, no. 12: 3765-3779.

13. del Mar Morales-Amaral, M., C. Gómez-Serrano, F.G. Acién, J.M. Fernández-Sevilla, and E. Molina-Grima. 2015. "Production of microalgae using centrate from anaerobic digestion as the nutrient source." Algal Research 9: 297-305.

14. Dalrymple, O.K., T. Halfhide, I. Udom, B. Gilles, J. Wolan, Q. Zhang, and S. Ergas. 2013. "Wastewater use in algae production for generation of renewable resources: a review and preliminary results." Aquatic Biosystems 9, no. 2.

15. Wang, L., M. Min, Y. Li, P. Chen, Y. Liu, Y. Wang, and R. Ruan. 2010. "Cultivation of Green Algae Chlorella sp. in Different Wastewaters from Municipal Wastewater Treatment Plant." Applied Biochemistry and Biotechnology 162, no. 4: 1174-1186.

16. Husnain, T., B. Mi, and R. Riffat. 2015. "A combined forward osmosis and membrane distillation system for sidestream treatment." Journal of Water Resource and Protection 7, no. 14: $1111-1120$.

17. Khiewwijit, R., H. Temmink, H. Rijnaarts, and K.J. Keesman. 2015. "Energy and nutrient recovery for municipal wastewater treatment: how to design a feasible plant layout?"

Environmental Modelling \& Software 68: 156-165.

18. National Association of Clean Water Agencies. 2015. Opportunities \& Challenges in Clean Water Utility Financing and Management: Financial Survey Highlights. Washington, DC: National Association of Clean Water Agencies.

19. Poole, K. (MicroBio Engineering), and R. Davis. November 2018. Personal communication.

20. Stack, C., P. Kodukula (Neochloris), L. Schideman (University of Illinois), and R. Davis. November 2018. Personal communication.

21. Main, D. 2015. "Two Numbers: Animal Manure a Growing Headache in America." Newsweek, December 8, 2015. https://www.newsweek.com/2015/12/18/two-numbers-animalmanure-growing-headache-america-402205.html. 